\title{
CATCHING THE WOVEN FABRIC WITH VACUUM GRIPPER
}

\author{
CUBRIC, G[oran]; NIKOLIC, G[ojko] \& SIGNJAR, S[anja]
}

\begin{abstract}
Applying vacuum grippers largely found its application in the catching and transfer the materials in all industries. Only in the textile and garment industry, because of the materials porosity is not widely applied. Therefore, we initiate the research of enhancing the use of vacuum gripper for textile materials manipulation. Tests have shown that the transfer of fabric required inlet pressure on the vacuum gripper a minimum of 5 bar. It has also been found that the application of this vacuum gripper is not suitable for taking one layer of fabric from material bundle.
\end{abstract}

Keywords: vacuum gripper, textile material, catching

\section{INTRODUCTION}

Sewing as a core process of non-rigid parts assembly is already highly automated. Besides clothing manufacturing, new materials for technical textiles expand the application areas of automated sewing. However, the handling processes around sewing are hardly automated. The required flexibility and dexterity can easily obtain only by manual assembly system. Automated handling of textiles due to their challenging material properties set a benchmark for handling of different nor-rigid materials like leather, paper, or foils. Any assembly process requires defined positioning and orienting of the workpieces to be mated. As the response of non-rigid parts to handling forces is less predictable, specific requirements emerge with respect to workpiece properties, type of placement, types of specific handling processes, as well as general process characteristics. [1].

Industrial manipulators which perform auxiliary operations can be divided into three groups. The first group performs the auxiliary operations prior to the sewing process. They collect, mark, put on the right track, and stack textile pieces in the working zone of an automatic sewing machine. The second group, sometimes called technological sewing robots, works in synchronization with sewing machines. They grip textile pieces, convey them along a required trajectory within the working zone of the automatic sewing machine, and supervise the distance between the needle and the edge of a textile piece, the number of stitches, their size and other technological parameters. The third group of manipulators puts the sewn pieces or garments on ironing presses or tables, removes semi-manufactured products, folds \& packs them, and loads them into the cases [2].

By replacing the vacuum pump with a simple ejector to achieve vacuum, started a widespread application to catch different subjects. The ability to easily catch various subjects with vacuum grippers is used for transporting workpieces from the bundle to the place of processing, from one place of processing to another, packing into containers, transfer containers etc. Vacuum is used for such jobs in almost all industries. Significantly, it has been applied in production processes and in particular in the assemblies. Wider application meets in the metal, electrical, wood, food, ceramics, glass and paper industry. It transferred various products such as eggs, fruit, canned goods, glass, bottles, ceramic tiles, metal sheets, metal and plastic products, wood veneer, paper, etc. [3].

The vacuum grippers have not yet found a wider application in the garment machinery. One reason is the permeability of the fabric and therefore the loss of vacuum, but other side effects such as retractable fabric in saliva, suspension pumps outside edges of fabric and therefore the inability to accurately place them on the application process work, etc. [4].

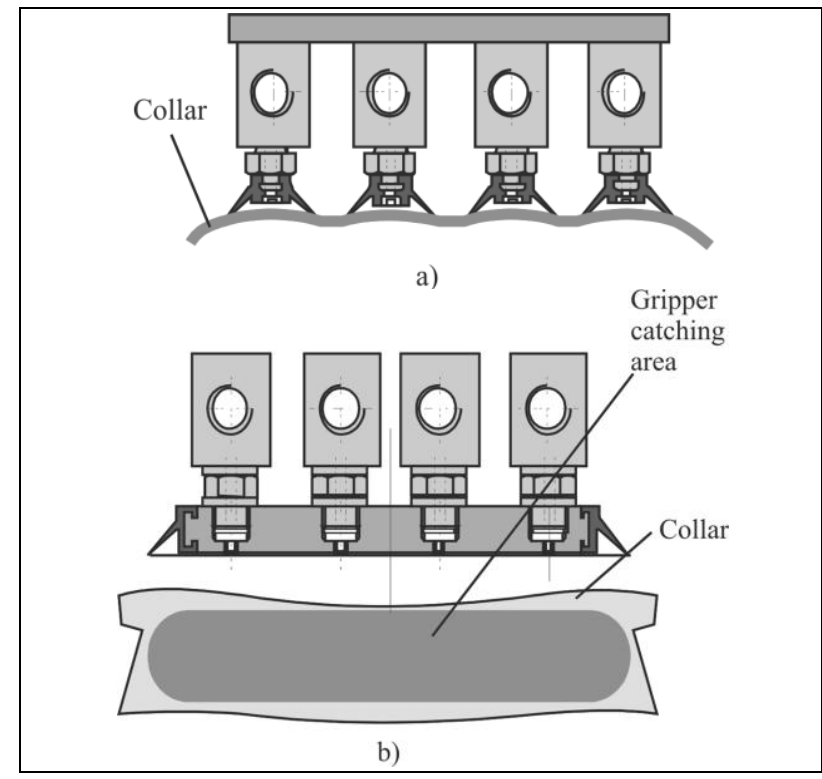

Fig. 1. Vacuum gripper for collar: a) construction of the standard grippers, b) special construction solutions

Because of the air permeability of textile materials, the application of vacuum grippers in garment technology is limited. Impermeable or less permeable materials such as plastics, impregnated materials, tightly woven polyester, paper, labels, etc. and workpieces of multiple layers after thermoplastic adhesive (called a head-fixation), etc. can be transferred by vacuum grippers. Because of the need to achieve a vacuum (the problem of leakage of material) gripper should cover as 
large an area of the workpiece in order to achieve a force sufficient to hold it, and it is necessary to design grippers (form) for a specific workpiece, Fig 1. [3]

Transfer workpiece with vacuum, such as taking out of bundle and transfer to another location, there are very practical problems. Namely, the separation of individual workpieces for various reasons is not achieved easily. Part held together by static electricity, partly due to the vacuum created between them, and in textile materials due to its permeability, vacuum engages the workpiece below the uppermost of which catches [3].

\section{EXPERIMENT}

The aim of this paper is to examine the possibility of capturing and transferring textile material (cloth) with vacuum gripper and testing the extent to which pressure that enters in the vacuum gripper depends on catching textile material respectively. Therefore, it is collected 16 different samples of woven fabrics that are cut to the size of $15 \times 15 \mathrm{~cm}$. To capture the fabric samples it is using the vacuum gripper company Norgren M/58102/20 type (Fig. 2), which has a maximum inlet pressure of 6 bar, maximum suction flow of $98 \mathrm{~L} / \mathrm{min}$ and a maximum vacuum pressure of -0.87 bar [5].

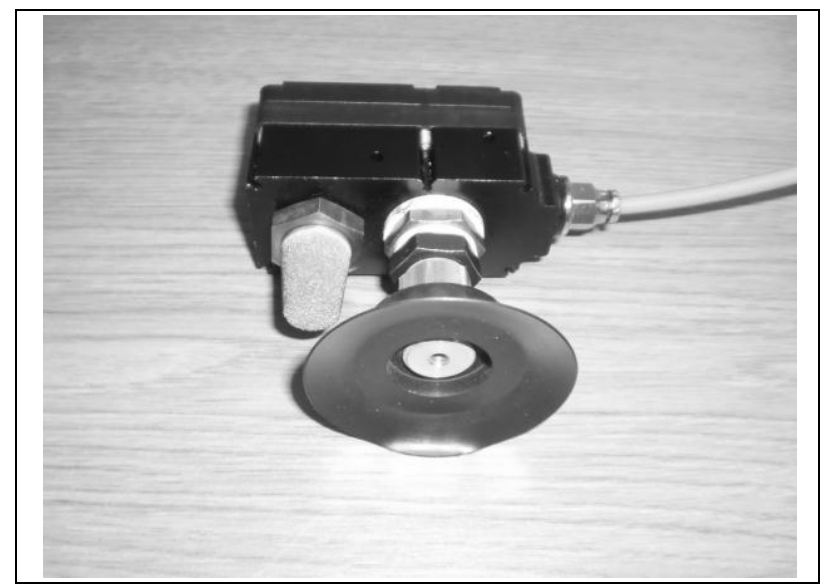

Fig. 1. Vacuum gripper

Before the test the thickness and surface mass of samples by ISO standards are defined (ISO 5084:1996, ISO 3801:1977), and also the number of threads per warp and weft on $1 \mathrm{~cm}$, Tab. 1 .

According to ISO 5084: 2004 fabric thicknesses is defined as the distance between two flat parallel metallic plates separated by a fabric, which is under a certain pressure. The measurement is carried out using calipers which must ensure the accuracy of the results at 0.01 $\mathrm{mm}$. Calipers consists of a substrate to which it puts the test material and the pressing material that presses against a certain force, and who is in a relationship with a part of the show and recording the results. Surface of the pressing and pressure during measurements depend on the investigated material and are usually defined in the contract. If it is not specifically provided for, above standard is recommended for testing the pressing surfaces of the usual $2000 \mathrm{~mm}^{2}$ and a pressure of $1 \mathrm{kPa}$. For each sample were performed 5 measurements at different locations on the sample, as a result of testing the mean value of the measurements. Figure 3 shows used calipers to measure the thickness of fabric.

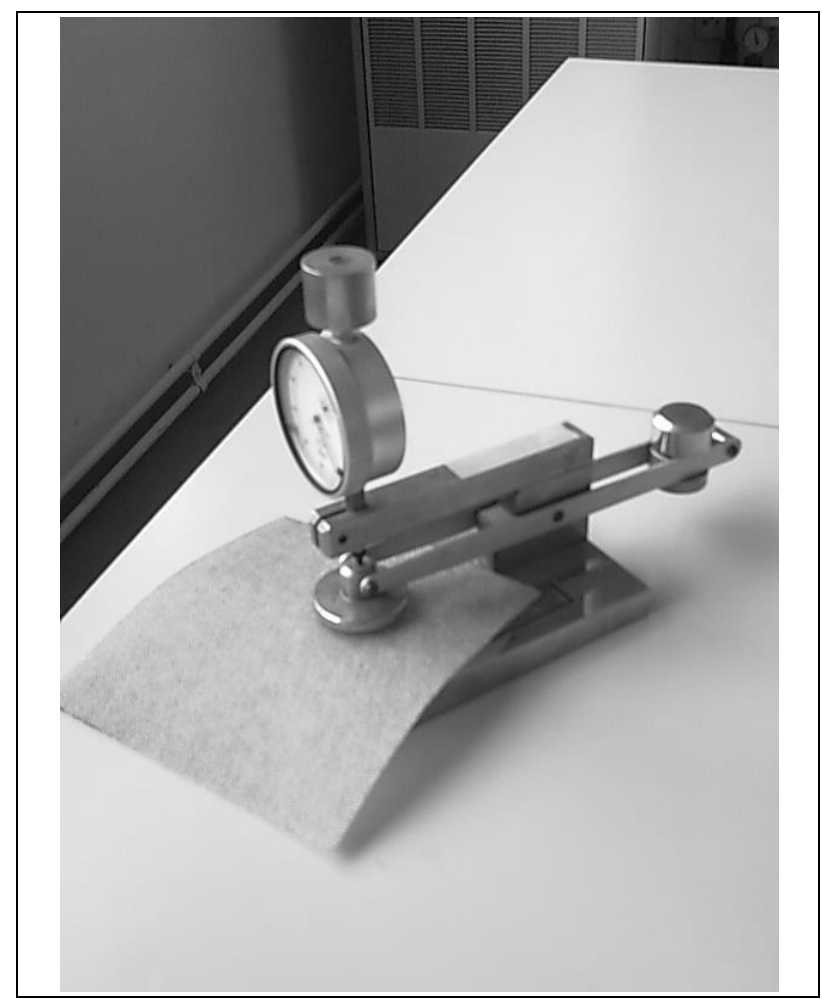

Fig. 3. Caliper to measure the thickness of fabric

According to ISO 3801: 2003 surface mass is the mass of $1 \mathrm{~m}^{2}$ fabric expressed in grams, i.e. units of surface mass is $\mathrm{g} / \mathrm{m}^{2}$. Samples are cut to the size of $15 \times 15 \mathrm{~cm}$, and then cut out the circular pattern of 100 $\mathrm{cm}^{2}$ using a special cutter, Fig 4.

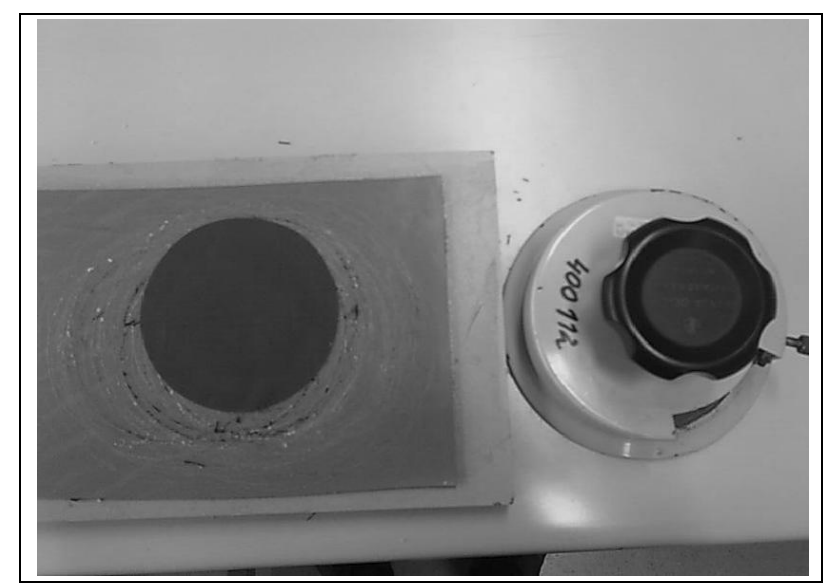

Fig. 4. Circular cut samples with special cutter

After that, the samples are pre-dried. To achieve a steady state must start from the dry sample. The sample to be examined must be exposed to pre-dried in the space that has no $\mathrm{RH}$ greater than $10 \%$ and temperature of 50 ${ }^{\circ} \mathrm{C}$. Steady state is achieved when the difference in mass of less than $0.5 \%$ for a period of $2 \mathrm{~h}$.

After that, the samples were placed in a desiccator relative humidity $65 \%$ at $20{ }^{\circ} \mathrm{C}$ for $24 \mathrm{~h}$. The sample must be in free state. Decanters with samples are being shut down and removed from the desiccator, weighed together and weigh the empty decanter. Than the value of 
the empty decanter is detracted from the value of the container with the sample.

The examination were performed so that on the flat surfaces of wood base laid one or two layers of samples, and the vacuum gripper is set in the middle of sample (Fig. 5a) or on the edge of the sample, Fig 5b. Inlet pressure to catch is changing from 2 to 6 bar. It was observed if in a given pressure sample can be lift up to a height of $15 \mathrm{~cm}$.

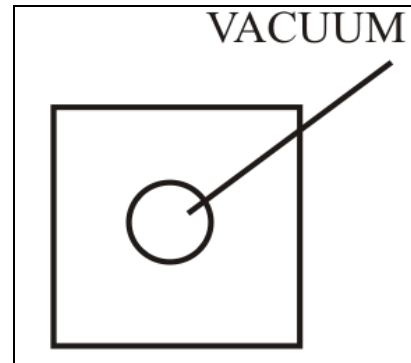

a)

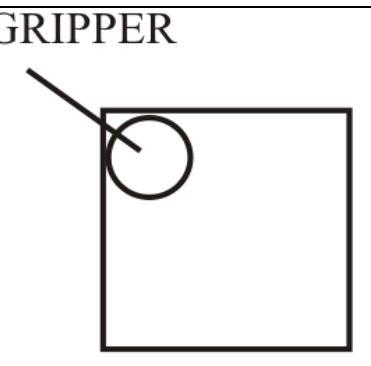

b)
Fig. 5. Position of the sample caching a) in the center, b) on the edge

Figure 6 shows the wiring diagram of the measuring equipment which is performed in the experiment. The measuring equipment consists of a digital manometer GDH 14 AN Greisinger electronic company which has an accuracy of 0.01 bar \pm 1 digit, Festo air pressure controller and other supporting elements.

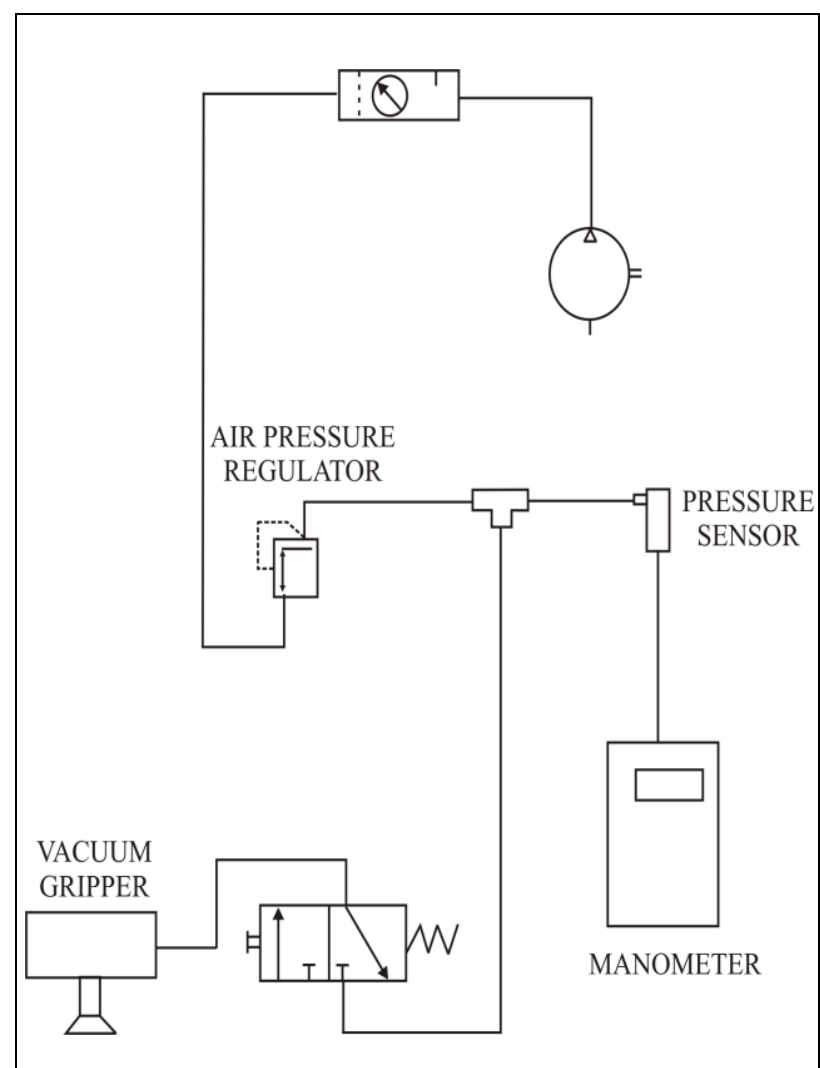

Fig. 6. Wiring diagram of the measuring equipment which is performed in the experiment

Figure 7 show the fabric transposition with a vacuum gripper.

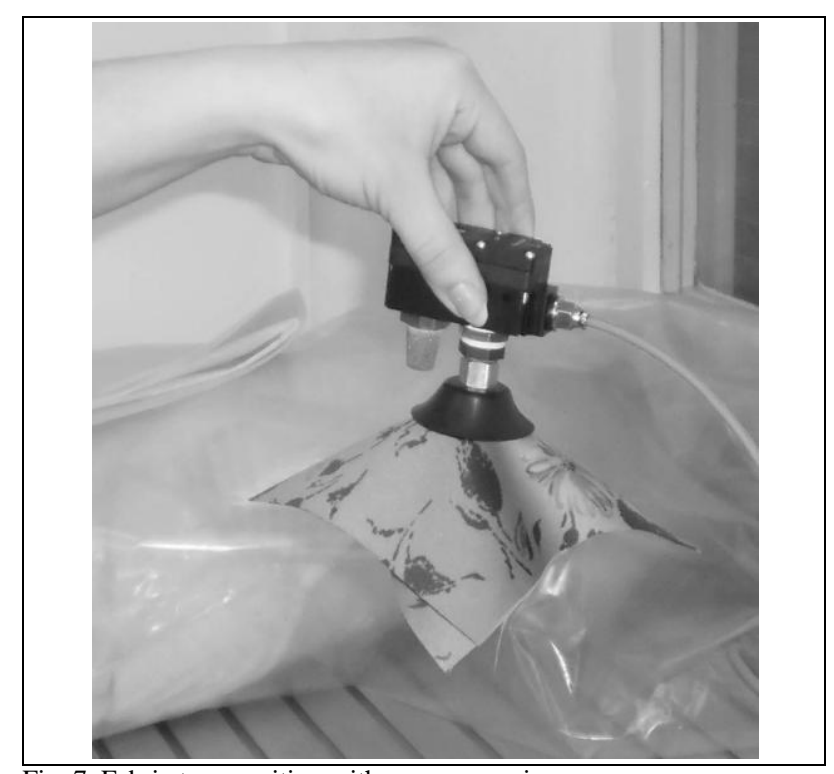

Fig. 7. Fabric transposition with a vacuum gripper

\begin{tabular}{|c|c|c|c|c|}
\hline \multirow[b]{2}{*}{ SAMPLE } & \multirow{2}{*}{$\begin{array}{c}\text { Sample } \\
\text { thickness } \\
{[\mathrm{mm}]}\end{array}$} & \multirow{2}{*}{$\begin{array}{c}\text { Surface } \\
\text { mass } \\
{\left[\mathrm{g} / \mathrm{m}^{2}\right]}\end{array}$} & \multicolumn{2}{|c|}{ Number of threads } \\
\hline & & & $\begin{array}{l}\text { Per warp } \\
\text { on } 1 \mathrm{~cm}\end{array}$ & $\begin{array}{l}\text { Per weft } \\
\text { on } 1 \mathrm{~cm}\end{array}$ \\
\hline 1 & 0,138 & 46,63 & 50 & 39 \\
\hline 2 & 0,156 & 52,53 & 37 & 30 \\
\hline 3 & 0,356 & 134,44 & 31 & 21 \\
\hline 4 & 0,37 & 118,22 & 31 & 28 \\
\hline 5 & 1,304 & 123,05 & 34 & 24 \\
\hline 6 & 1,376 & 111,81 & 29 & 26 \\
\hline 7 & 1,446 & 126,39 & 37 & 30 \\
\hline 8 & 1,492 & 161,75 & 30 & 25 \\
\hline 9 & 1,506 & 164,02 & 49 & 30 \\
\hline 10 & 1,572 & 208 & 42 & 27 \\
\hline 11 & 1,654 & 266,88 & 37 & 25 \\
\hline 12 & 1,662 & 279,42 & 22 & 19 \\
\hline 13 & 1,666 & 287,01 & 32 & 27 \\
\hline 14 & 2,104 & 327,68 & 29 & 21 \\
\hline 15 & 2,184 & 476,4 & 27 & 19 \\
\hline 16 & 3,2 & 969,59 & 21 & 17 \\
\hline
\end{tabular}

Tab. 1. Characteristics of the examined fabric samples

\section{RESULTS AND DISCUSSION}

Tables 2 and 3 show the results of capturing one / two layers of fabric where the mark 1 denotes the lifting only one / both layers of fabric, 2 - lifting and holding up the upper layer of fabric, 3 - lifting up one / both layers and fall, 4 - no lifting of sample and 5 - gripper is stitch to the base. Mark $\mathrm{E}$ indicates the position of gripper on the edge of the fabric and mark $\mathrm{C}$ the position in the center of the fabric.

Observing the results of capturing one layer of woven fabric with vacuum gripper (Table. 2) show that at low pressures ( 2 and 3 bar) no sample is raised to a height of 
$15 \mathrm{~cm}$. Only at a pressure of 4 bar comes to catching and raising materials. However, capturing and lift up was achieved only by six samples $(7,8,9,10,11$ and 13$)$ that have a thickness of between 1.45 and $1.65 \mathrm{~mm}$ and has a gripper position at the center of the sample. When the gripper is placed on the edge of the sample, at the same pressure of 4 bar it lift up four more samples (samples 3 , 4, 5 and 6). From the above it can be concluded that the materials that are very thin (thickness less than 0.16 $\mathrm{mm}$ ), or have a small surface mass (less than $100 \mathrm{~g} / \mathrm{m}^{2}$ ) are too easy to manipulate with little pressure. Also, it can be concluded that materials which have a thickness greater than $2 \mathrm{~mm}$ and surface mass greater than 300 $\mathrm{g} / \mathrm{m}^{2}$ are too heavy for the lower pressure. Increasing a pressure to 5 bar, gripper sticks to the base by the samples with small thickness. The only thing they managed to lift is samples 11-13. At 6 bar situation is similar as at 5 bar, only in catching samples on the edge of the material changes occur. It managed to raise most of the samples.

Observing the results of transferring two layers of fabric, shown in the Table. 3, it can be seen that the low pressure ( 2 and 3 bar) do not achieve useful results. Only the upper layer of sample 1 failed to raise at 3 bar when gripper is set on the edge of the material. At a pressure of 4 and 5 bar it manages to lift the upper layer or two layers of material, however it is not possible to determine the regularity in order to the thickness of the material. At 6 bar most samples are successful lifted when the gripper is on the edge of the samples, except for samples 14,15 and 16 which have the greatest thickness, and surface mass.

Observed both tables, shows that the manipulation of

\begin{tabular}{|c|c|c|c|c|c|c|c|c|c|c|}
\hline \multirow{3}{*}{ Sample } & \multicolumn{10}{|c|}{ Pressure } \\
\hline & \multicolumn{2}{|c|}{2 bar } & \multicolumn{2}{|c|}{3 bar } & \multicolumn{2}{|c|}{4 bar } & \multicolumn{2}{|c|}{5 bar } & \multicolumn{2}{|c|}{6 bar } \\
\hline & E & $\mathrm{C}$ & E & $\mathrm{C}$ & E & $\mathrm{C}$ & E & $\mathrm{C}$ & $\mathrm{E}$ & $\mathrm{C}$ \\
\hline 1 & 3 & 4 & 3 & 5 & 3 & 5 & 3 & 5 & 1 & 5 \\
\hline 2 & 4 & 4 & 3 & 5 & 3 & 5 & 3 & 5 & 5 & 5 \\
\hline 3 & 3 & 4 & 3 & 4 & 1 & 5 & 1 & 5 & 1 & 5 \\
\hline 4 & 3 & 4 & 3 & 4 & 1 & 3 & 1 & 5 & 1 & 1 \\
\hline 5 & 3 & 4 & 3 & 4 & 1 & 3 & 1 & 1 & 1 & 1 \\
\hline 6 & 3 & 4 & 3 & 4 & 1 & 4 & 1 & 5 & 1 & 5 \\
\hline 7 & 3 & 4 & 3 & 4 & 1 & 1 & 1 & 5 & 1 & 5 \\
\hline 8 & 3 & 4 & 3 & 4 & 1 & 1 & 1 & 5 & 1 & 5 \\
\hline 9 & 3 & 4 & 3 & 4 & 1 & 1 & 1 & 5 & 1 & 1 \\
\hline 10 & 3 & 4 & 3 & 4 & 1 & 1 & 1 & 5 & 1 & 5 \\
\hline 11 & 3 & 4 & 3 & 4 & 1 & 1 & 1 & 1 & 1 & 1 \\
\hline 12 & 3 & 4 & 3 & 4 & 3 & 4 & 3 & 1 & 1 & 5 \\
\hline 13 & 3 & 4 & 3 & 4 & 3 & 1 & 3 & 1 & 1 & 1 \\
\hline 14 & 4 & 4 & 3 & 4 & 3 & 4 & 3 & 4 & 3 & 1 \\
\hline 15 & 3 & 4 & 3 & 4 & 3 & 3 & 3 & 4 & 3 & 1 \\
\hline 16 & 4 & 4 & 3 & 4 & 3 & 4 & 3 & 4 & 3 & 4 \\
\hline
\end{tabular}

Tab. 2. The results of capturing one layers of fabric with vacuum gripper samples could be easily transferred from one place to another. However, the application of vacuum gripper is not suitable for taking one layer of fabric from material bundle. Likewise it is evident that better results are obtained when the gripper is set on the edge of material, than when it is in the middle of the material.

\begin{tabular}{|c|c|c|c|c|c|c|c|c|c|c|}
\hline \multirow{3}{*}{ Sample } & \multicolumn{10}{|c|}{ Pressure } \\
\hline & \multicolumn{2}{|c|}{2 bar } & \multicolumn{2}{|c|}{3 bar } & \multicolumn{2}{|c|}{4 bar } & \multicolumn{2}{|c|}{5 bar } & \multicolumn{2}{|c|}{6 bar } \\
\hline & $\mathrm{E}$ & $\mathrm{C}$ & $\mathrm{E}$ & $\mathrm{C}$ & $\mathrm{E}$ & $\mathrm{C}$ & $\mathrm{E}$ & $\mathrm{C}$ & $\mathrm{E}$ & $\mathrm{C}$ \\
\hline 1 & 3 & 4 & 2 & 5 & 1 & 5 & 1 & 5 & 1 & 5 \\
\hline 2 & 4 & 4 & 4 & 4 & 2 & 5 & 2 & 5 & 2 & 5 \\
\hline 3 & 3 & 4 & 3 & 4 & 1 & 2 & 1 & 2 & 1 & 2 \\
\hline 4 & 3 & 4 & 3 & 4 & 3 & 3 & 3 & 3 & 1 & 1 \\
\hline 5 & 3 & 4 & 3 & 2 & 3 & 3 & 3 & 2 & 1 & 1 \\
\hline 6 & 3 & 4 & 3 & 4 & 3 & 2 & 3 & 2 & 1 & 2 \\
\hline 7 & 3 & 4 & 3 & 4 & 3 & 2 & 2 & 2 & 1 & 2 \\
\hline 8 & 3 & 4 & 3 & 4 & 3 & 5 & 3 & 5 & 1 & 5 \\
\hline 9 & 3 & 4 & 3 & 4 & 3 & 2 & 3 & 2 & 2 & 2 \\
\hline 10 & 3 & 4 & 3 & 4 & 2 & 5 & 2 & 5 & 1 & 5 \\
\hline 11 & 3 & 4 & 3 & 4 & 1 & 1 & 1 & 1 & 1 & 1 \\
\hline 12 & 3 & 4 & 3 & 4 & 3 & 2 & 3 & 1 & 1 & 1 \\
\hline 13 & 3 & 4 & 3 & 4 & 3 & 4 & 3 & 2 & 2 & 2 \\
\hline 14 & 4 & 4 & 3 & 4 & 3 & 4 & 3 & 4 & 3 & 3 \\
\hline 15 & 3 & 4 & 3 & 4 & 3 & 4 & 3 & 4 & 3 & 1 \\
\hline 16 & 4 & 4 & 3 & 4 & 3 & 3 & 3 & 2 & 3 & 2 \\
\hline
\end{tabular}

Tab. 3. The results of capturing two layers of fabric with vacuum gripper

\section{CONCLUSION}

On the basis of the study it can be concluded that the transfer of fabric required inlet pressure on the vacuum gripper a minimum of 5 bar. It has also been found that the application of this vacuum gripper is not suitable for taking one layer of fabric from material bundle. The aim of further research is to determine the acceptability of the use of a vacuum gripper for handling the knitted fabric and nonwovens, and other fabrics used in the clothing industry (leather, lace, etc).

\section{REFERENCES}

[1] Seliger, G.; Szimmat, F.; Niemeier, J. \& Stephan, J. (2003). AutomatedHandling of Non-RigidParts, CIRP Annals Manufacturing Technolog,y Vol 52, Issue 1, 21-24

[2] Kondratas, A. (2005). Robotic Gripping Device for Garment Handling Operations and Its Adaptive Control, Fibres \& Textiles in Eastern Europe, Vol. 13, No. 4 (52) October / December 2005, 84-89

[3] Nikolić, G. (1997). Research into the application of vacuum transport workpieces on automatic sewing machines, Tekstil, Vol. 46 No. 11, 635-639

[4] Nikolić, G.; Katalinić, B.; Rogale, D.; Jerbić, B. \& Čubrić G. (2008) Robots \& Applications in textile and clothing industry, Zrinski, ISBN 978-953-7105-22-8, Zagreb

[5] http://www.riteh.uniri.hr/zav_katd_sluz/zvd_kons_stroj/nas $/ \mathrm{ms} / \mathrm{m}$ s_2011-2012/MS\%20-\%20P05.pdf, Accessed: 2012-07-10 